\title{
A Goniopora stokesi community at Tatsugasako, Otsuki, Kochi, Japan: a new northernmost specimen-based record
}

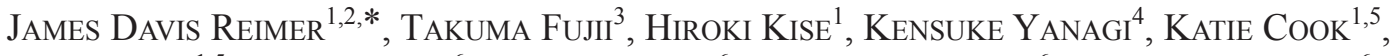

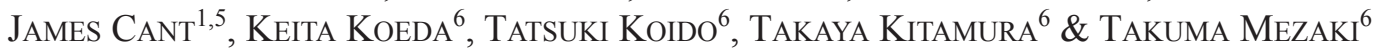 \\ ${ }^{I}$ Molecular Invertebrate Systematics and Ecology Laboratory, Graduate School of Engineering and Science, University of the Ryukyus, 1 \\ Senbaru, Nishihara, Okinawa 903-0213, Japan \\ ${ }^{2}$ Tropical Biosphere Research Center, University of the Ryukyus, 1 Senbaru, Nishihara, Okinawa 903-0213, Japan \\ ${ }^{3}$ International Center for Island Studies, Kagoshima University, Naze-Minatomachi 15-1-6F, Amami, Kagoshima 894-0026, Japan \\ ${ }^{4}$ Coastal Branch of Natural History Museum and Institute, Chiba, Yoshio 123, Katsuura, Chiba 299-5242, Japan \\ ${ }^{5}$ School of Biology, University of Leeds, Leeds LS2 9JT, United Kingdom \\ ${ }^{6}$ Kuroshio Biological Research Foundation, 560 Nishidomari, Otsuki, Kochi 788-0333, Japan
}

Received 23 January 2020; Accepted 1 March 2020 Responsible Editor: Shigeaki Kojima

doi: $10.3800 /$ pbr. 15.185

\begin{abstract}
The zooxanthellate scleractinian species Goniopora stokesi is widely distributed across the Indo-Pacific Ocean, and in Japan the northernmost records of this species are from Tatsukushi, Kochi on Shikoku, although these records are not associated with specimens deposited in museums. The species is unique among Goniopora in that it lives on soft bottom sediment, forming free-living colonies, and produces asexual daughter colonies, or 'polyp balls,' via budding from parent colonies. Here we report on a large $G$. stokesi community from Otsuki, Kochi, Japan, representing the northernmost specimen-based record of the species. Specimen-based records are important as verifiable baseline data in light of global warming and climate change, which is expected to drastically effect the marine flora and fauna of Kochi and surrounding areas.
\end{abstract}

Key words: Anthozoa, Scleractinia, temperate region, hard coral, free-living

Goniopora stokesi Milne Edwards \& Haime, 1851 is known to form large communities on soft substrates such as sandy bottoms, and is widely distributed in the Indo-Pacific Ocean (Veron 2000), including reports in Japan from Yaeyama Islands, Okinawa Islands, Tanegashima Island, Amakusa Islands, Miyakejima Island, and Tatsukushi, Kochi, based on photographs in Veron (1992), as well as from Iriomotejima Island and Okinawajima Island (Kitano et al. 2013), and Amami-oshima Island (Uyeno et al. 2016) based on specimens. The species is categorized as near-threatened in the IUCN Red List, and is commercially important in the aquarium trade (Sheppard et al. 2008). From an ecological point of view, G. stokesi communities can add complexity and rugosity to an otherwise flat sea bottom, and provide habitat for numerous associated organisms. Individual G. stokesi colonies form large free-living "balls" that are unattached to any hard substrate, and are instead found on sandy bottoms. In large stands, new colonies appear to primarily be clones generated asexually via budding/bail-out, a reproductive method unique

*Corresponding author: James Davis Reimer; E-mail, jreimer@sci.uryukyu.ac.jp to this species among Scleractinia (Scheer 1960; Rosen \& Taylor 1969; Kitano et al. 2013), although similar strategies are known from the order Zoantharia (Acosta et al. 2005; Gonzalez-Munoz et al. 2019). Although similar Goniopora communities have been reported from subtropical Japan, the numbers of colonies reported has been small and across only a few known locations, and molecular analyses have shown these communities to consist of species other than G. stokesi (Kitano et al. 2013). As well, some previous records are unclear about what exactly they are based on (e.g. specimens in a private collection, or field observations, etc., see Veron 1992), making confirmation of these data often difficult given the complexity of accurate species identifications.

The presence of an aggregation of Goniopora stokesi at Tatsugasako (also known as Ba-hama), Otsuki, Kochi, Japan $\left(32^{\circ} 51^{\prime \prime \prime} \mathrm{N}, 132^{\circ} 39^{\prime \prime} \mathrm{E}\right)$ had been known for several years by local divers (Figs. 1, 2). Species identification was confirmed via the presence of asexual daughter colonies ('polyp balls') visible in situ and on collected specimens (Fig. 3). Assessments of the size and density of the community were carried out on September 1, 2019 and December 13, 2019 by the authors, with in situ photographs and a rough estimate of the 


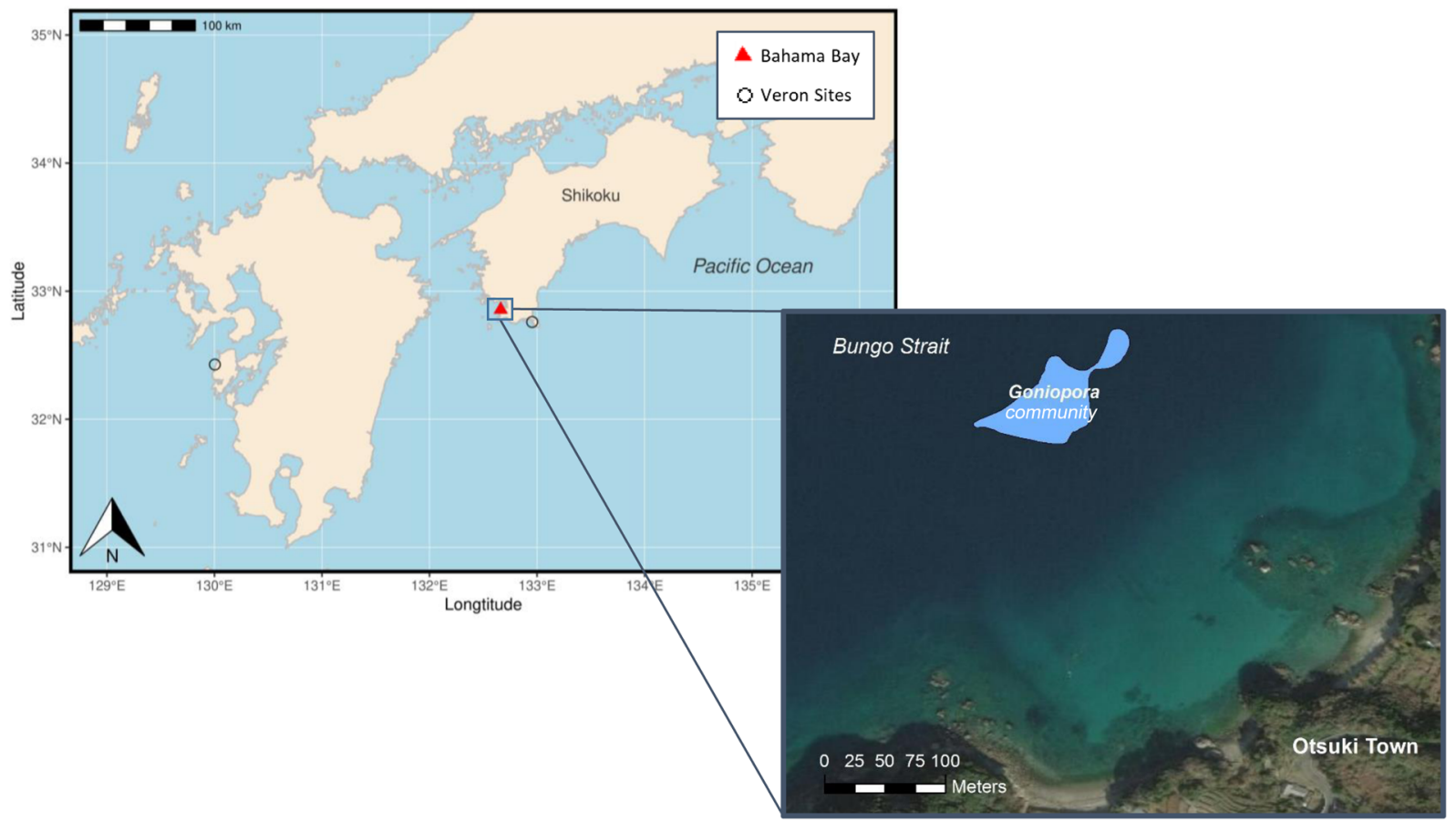

Fig. 1. Map of the Tatsugasako (Ba-hama) dive site including the relative location and size of the Gonipora stokesi community.

size of the community acquired via underwater measurement (Fig. 1). Specimens of G. stokesi from this study are deposited in the Kagoshima University Museum under the collection number KAUM-CN-15. For more detailed location information, please contact the corresponding author.

Colonies of $G$. stokesi were observed at Ba-hama at depths between 25 to $30 \mathrm{~m}$, with no colonies either deeper or shallower. The density of colonies averaged $40 \%$ and reached close to $80 \%$ coverage of the sandy bottom (Fig. 2), with colonies ranging in size from small daughter colonies approximately one $\mathrm{cm}$ in diameter to large colonies approximately $6-10 \mathrm{~cm}$ in diameter (Fig. 3). Almost no other anthozoans were observed among the G. stokesi colonies except for a single bleached Goniopora tenuidens (Quelch, 1886) colony. The total area covered by the community was estimated at approximately 120 by $90 \mathrm{~m}$, or $10,800 \mathrm{~m}^{2}$.

Although it does not appear on dive location guide maps (e.g. https://livedoor.blogimg.jp/johnny74656/imgs/a/2/a2d27b f4.jpg), it is not thought that this community is a recent appearance to the area. The location of this large community far north from most previously known specimen-based, confirmed records in the Ryukyu Islands (Kitano et al. 2013; Uyeno et al. 2016) is somewhat surprising. However, this current site is only slightly north of previous records from Unohae and Hirabae, Tosashimizu, Kochi (Veron 1992), although no specimens in museums, or exact latitude and longitude coordinates exist for these previous records. More recent examinations of soft-bottom Goniopora in Japan have shown other communities to not consist of G. stokesi, but instead of other Goniopora species (Kitano et al. 2013).

While the current report is simply a new specimen-based

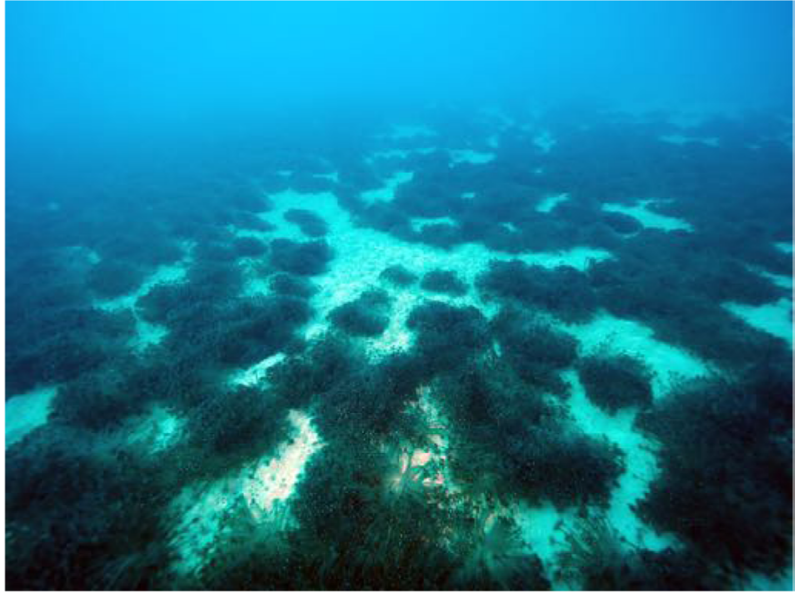

Fig. 2. Goniopora stokesi community in situ at the Tatsugasako (Ba-hama) dive site.

record of a species, this kind of data is becoming increasingly important given that the temperate Kuroshio region in Japanese waters is already undergoing drastic marine faunal changes due to ongoing global warming (e.g. Tanaka et al. 2012). Establishing firm records of the expanding range limits of species allows researchers to track the migration of species under climate change (Thomas et al. 2001). While such work is challenging for terrestrial species, it requires even more effort for marine species. Additionally, while many surveys have focused on shallow water zooxanthellate coral communities in the temperate regions of Japan, there is much knowledge to be gained from surveys in understudied areas such as sandy bottoms, rubble zones, mesophotic areas, and inner 

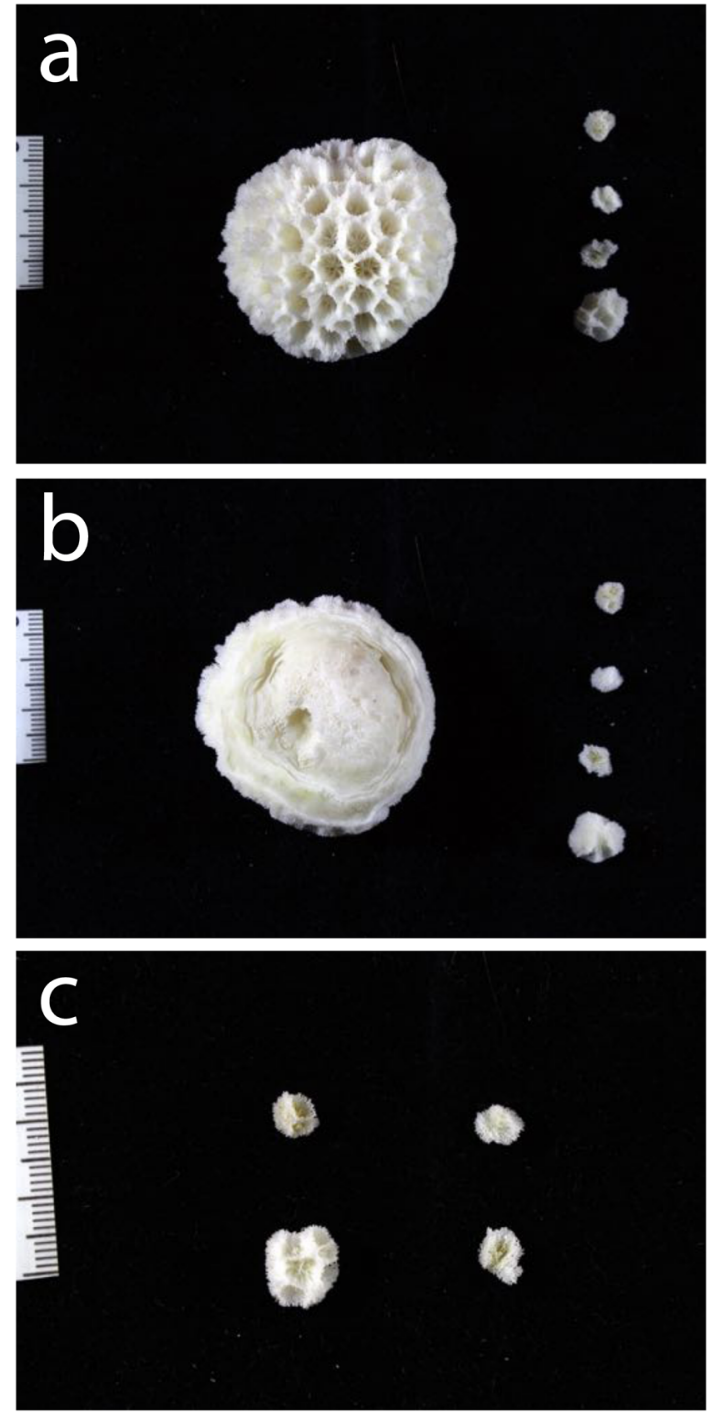

Fig. 3. Goniopora stokesi specimen KAUM-CN-15 showing a) mother and daughter colonies (top-side view), b) mother and daughter colonies (bottom-side view) and c) daughter colonies. Rulers in $\mathrm{mm}$ and $\mathrm{cm}$.

bays (Obuchi et al. 2009). A full understanding of the marine benthic fauna of the temperate region of Japan requires more of such research.

\section{Acknowledgements}

Dr. Masami Obuchi (Education Center, Manazuru Town Office) is thanked for the initial suggestion of the dive site. The authors thank Dr. Hironobu Fukami (Miyazaki Uni- versity) and Dr. Francesca Benzoni (University of Milano/ King Abdullah University of Science and Technology) for confirmation of species identification of the specimens, and Dr. Helmut Zibrowius for information on references and Goniopora stokesi. TF was supported by JSPS KAKENHI (JP17K15198 and JP17H01913) grants and the "Establishment of Research and Education Network on Biodiversity and Its Conservation in the Satsunan Islands" project of Kagoshima University adopted by the Ministry of Education, Culture, Sports, Science and Technology, Japan. KC and JC were supported by the Winifred Scott Foundation.

\section{References}

Acosta A, Sammarco PW, Duarte LF (2005) New fission processes in the zoanthid Palythoa caribaeorum: description and quantitative aspects. Bull Mar Sci 76: 1-26.

Kitano YF, Obuchi M, Uyeno D, Miyazaki K, Fukami H (2013) Phylogenetic and taxonomic status of the coral Goniopora stokesi and related species (Scleractinia: Poritidae) in Japan based on molecular and morphological data. Zool Stud 52: 25.

González-Muñoz R, Tello-Musi JL, Reimer JD (2019) First record of "polyp-ball colonies" produced by Zoanthus sociatus (Cnidaria, Anthozoa, Zoantharia). Mar Biodivers 49: 2197-2198.

Milne Edwards H, Haime J (1851) Recherches sur les polypiers. Memoire 7. Monographie des Poritides. Ann Sci Nat Zool Series 3, 16: 21-70.

Obuchi M, Kogo I, Fujita Y (2009) A new brooding feather star of the genus Dorometra (Echinodermata: Crinoidea: Comatulida: Antedonidae) from the Ryukyu Islands, southwestern Japan. Zootaxa 2008: 61-68.

Rosen BR, Taylor JD (1969) Reef coral from Aldabra: new mode of reproduction. Science 166(3901): 119-121.

Scheer G (1960) Viviparie bei Steinkorallen. Naturwissenschaften 47 (10): 238-239.

Sheppard A, Fenner D, Edwards A, Abrar M, Ochavillo D (2008) Goniopora stokesi. The IUCN Red List of Threatened Species 2008: e.T133668A3855942.

https://dx.doi.org/10.2305/IUCN.UK.2008.RLTS.T133668A3855942. en. Downloaded on 28 February 2020.

Tanaka K, Taino S, Haraguchi H, Prendergast G, Hiraoka M (2012) Warming off southwestern Japan linked to distributional shifts of subtidal canopy-forming seaweeds. Ecol Evol 2(11): 2854-2865.

Thomas CD, Bodsworth EJ, Wilson RJ, Simmons AD, Davies ZG, Musche M, Conradt L (2001) Ecological and evolutionary processes at expanding range margins. Nature 411: 577-581.

Uyeno D, Fujii T, Kitano Y, Uyeno H, Yokoyama S (2016) A distributional record of the zooxanthellate coral Goniopora stokesi Milne Edwards and Haime, 1851 (Anthozoa: Scleractinia: Poritidae) from coastal waters in Amami and Kakeroma islands, the Ryukyu Islands. Nature of Kagoshima 42: 477-481.

Veron JE (1992) Conservation of biodiversity: a critical time for the hermatypic corals of Japan. Coral Reefs 11: 13-21.

Veron JE, Stafford-Smith M (2000) Corals of the World. Volumes 1-3. Australian Institute of Marine Science, Townsville, Australia. 1382 pp. 